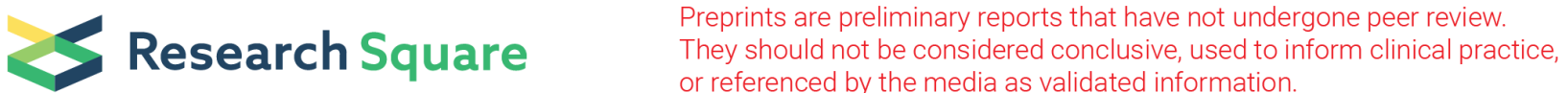 \\ Impacts of the COVID-19 pandemic on mental and psychosocial health among patients undergoing active cancer treatment: An international survey
}

\section{Hallie Dau}

The University of British Columbia Faculty of Pharmaceutical Sciences

\section{Alyssa Howren}

The University of British Columbia Faculty of Pharmaceutical Sciences

\section{Abdollah Safari}

The University of British Columbia Faculty of Pharmaceutical Sciences

\section{Jonathan Loree}

BC Cancer Agency: British Columbia Cancer Agency

\section{Helen McTaggart-Cowan}

BC Cancer Agency: British Columbia Cancer Agency

\section{Stuart Peacock}

BC Cancer Agency: British Columbia Cancer Agency

\section{Frederick Crawford}

BC Cancer Agency: British Columbia Cancer Agency

Mary A De Vera ( $\triangle$ mdevera@mail.ubc.ca)

The University of British Columbia Faculty of Pharmaceutical Sciences https://orcid.org/0000-0002-2205-2683

\section{Research Article}

Keywords: cancer, COVID-19, mental health, psychosocial, international

Posted Date: March 18th, 2021

DOI: https://doi.org/10.21203/rs.3.rs-256837/v1

License: (a) (1) This work is licensed under a Creative Commons Attribution 4.0 International License. Read Full License 


\section{Abstract}

Background: There is limited information on the impact of the COVID-19 pandemic on the mental health of patients with cancer. Our objective was to evaluate the mental and psychosocial health impacts of the COVID-19 pandemic among individuals undergoing active cancer treatment and compare outcomes among those diagnosed $<50$ and $\geq 50$ years of age.

Methods: We administered an international, Internet-based cross-sectional survey. We used validated scales to assess anxiety (GAD-7), depression (PHQ-9), social isolation (LSNS6) and loneliness (UCLA3) and used multivariable regression models to identify determinants.

Results: Altogether 238 ( $126<50$ years and $112 \geq 50$ years) participants undergoing active treatment for cancer completed the survey. Overall, many participants experienced anxiety (26.6\%), depression (30.0\%), loneliness (43.3\%), and social isolation (19.8\%). Younger participants were more likely to experience anxiety (GAD-7 $<50$ years $7.4 \pm 5.1 \mathrm{vs}$. $\geq 50$ years $5.9 \pm 5.9$ [p-value $0.042]$ ) and older participants were more likely to experience social isolation (LSNS6 <50 years $17.8 \pm 5.8$ vs. $\geq 50$ years $15.9 \pm$ 6.0 for those [p-value 0.019]). Determinants of anxiety identified in multiple linear regression included age at cancer diagnosis ( $B=-0.05$; $p$-value 0.047$)$, worrying about paying household expenses $(B=1.42 ; p$-value $=0.034)$, social isolation $(B=2.15 ; p$-value $0.017)$ and depression $(B=6.67 ; p$-value $<.0001)$. Determinants of depression included loneliness $(B=3.77 ; p$-value $<.0001)$ and

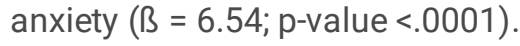

Conclusions: The results of our study indicate the negative impact that the COVID-19 pandemic has had on patients with cancer undergoing active treatment across the age spectrum.

\section{Background}

The COVID-19 pandemic has led to a global increase in the demand for mental health care. ${ }^{1,2}$ Consideration is needed to understand the mental health of patients with cancer during the COVID-19 pandemic, given that they are among the most vulnerable populations with higher risk of infection as well as development of severe illnesses or complications. ${ }^{3,4}$ Despite anecdotal reports, research on the mental health impacts of the COVID-19 pandemic among patients with cancer is limited. Košir et al. ${ }^{5}$ surveyed 177 adolescent and young adults ( $\leq 39$ years) with cancer and found that $62 \%$ reported feeling more anxious during, than before the COVID-19 pandemic. However, this study is limited to a younger patient population and its descriptive nature precluded understanding on potential reasons or associated factors. Evidence for age-related differences on mental health impacts of the COVID-19 pandemic in the general population ${ }^{6-8}$ underscores the need for specific research among cancer patients of all ages. As such, we evaluated mental and psychosocial health outcomes and determinants as well as patterns of mental health care utilization among individuals undergoing active cancer treatment during the COVID-19 pandemic. We considered adult patients across the age spectrum and define "young-onset" patients as those diagnosed with cancer before the age of 50 (<50 years) and "average-age-onset or older" patients as those diagnosed at or over the age of 50 ( $\geq 50$ years). ${ }^{9,10}$

\section{Methods}

\section{Study design and participants}

This study was nested within an international Internet-based cross-sectional study that aims to better understand the impacts of COVID-19 on care and outcomes of patients undergoing active cancer treatment. We recruited participants through authors' social media channels (e.g., Twitter, Facebook, and Instagram) and cancer organizations. Participants were eligible if they 1) were 18 years of age or older; 2) had been diagnosed with cancer; 3) were currently undergoing cancer treatment; and 4) spoke English or French.

\section{Survey}

The survey was hosted online using Qualtrics, a platform supported by our institution and compliant with the British Columbia (BC) Freedom of Information and Protection of Privacy Act. Altogether the survey consisted of nine sections and 80 questions 
including demographic information, cancer history and characteristics, and current treatment(s) for cancer (Supplement 1)

We used validated scales to assess mental health outcomes of interest, specifically, depression and anxiety. The Generalized Anxiety Disorder Scale-7 (GAD-7) contains seven items relating to anxiety and asks how often, in the past two weeks, each item bothered participants. Responses were scored zero to 27 and we applied a cut-off of $\geq 10$ to identify the presence of anxiety. ${ }^{11}$ The Patient Health Questionnaire (PHQ-9), used to measure depression, comprised nine items asking participants how often they have been bothered by nine listed problems over the last 2 weeks. Items are summed to obtain a score ranging from 0 to $27^{12}$ and we applied a cut-off of $\geq 10$ to define the presence of depression. ${ }^{13} \mathrm{~W}$ also asked participants about mental health care utilization during the COVID-19 pandemic, including whether or not they had taken any medications for their mental health, types of mental health care providers accessed, and mode of care delivery (e.g., virtual).

We used validated measures to assess psychosocial outcomes, specifically social isolation using the Lubben Social Network Scale (LSNS6) and loneliness using the UCLA Loneliness Scale Version 3 (UCLA3). The LSNS6 consists of six questions which ask about a respondent's interactions with family and friends. Responses are scored zero to 30 and the presence of social isolation was defined as a LSNS6 score $<12 .{ }^{14}$ The UCLA3 consists of three questions on loneliness and each question is scored one to three and the presence of loneliness was identified among those who scored $>6 .{ }^{15,16}$ We also asked questions regarding the financial impacts of the COVID-19 pandemic including participants' employment status before the COVID-19 pandemic and current employment status. Additionally, we asked participants whether they had any household expenses they were worried about paying as a result of the COVID-19 pandemic.

\section{Analysis}

We used descriptive statistics including counts and proportions for categorical variables and means and standard deviation for continuous variables. Chi-square tests and t-tests were used to compare characteristics and outcomes between patients diagnosed with cancer $<50$ and $\geq 50$ years of age. Multivariable linear regression models evaluated determinants of anxiety and depression using scores on respective scales. Variables considered included age at cancer diagnosis (e.g., $<50$ years versus $\geq 50$ years), as well as other factors we surveyed (e.g., worries about specific expenses, social isolation, loneliness). Analysis was performed in SAS 9.4 (SAS Institute Inc., Cary, NC, USA).

\section{Ethical approval}

Ethical approval was received from the University of British Columbia Research Ethics Board (\#H20-01087). Informed consent was obtained from all study participants. Furthermore, the research team ensured the confidentiality of all participants. Research files were kept on secure firewall servers and only members of the research team had access to the data.

\section{Results}

Between 04/23/2020 and 08/04/2020, 238 individuals diagnosed with cancer and undergoing active treatment completed the survey. Among them, 126 (52.9\%) were diagnosed with cancer $<50$ years and $112(47.1 \%) \geq 50$ years of age (Table 1$)$. With respect to cancer characteristics, the most common cancers reported were breast ( $<50$ years, $23.8 \%$; $\geq 50$ years, $28.6 \%$ ) and colorectal cancer ( $<50$ years, $33.3 \% ; \geq 50$ years, $16.1 \%$ ). The majority of participants in both age groups were diagnosed with stage IV cancer ( $<50$ years, $43.2 \% ; \geq 50$ years, $46.4 \%$ ). Lastly, $23.1 \%$ of individuals $<50$ years and $11.7 \% \geq 50$ years reported undergoing testing for COVID-19 with one individual in each age group reporting a positive result. Prior to the COVID-19 pandemic, 75 (59.5\%) of participants $<50$ years and 31 (27.9\%) of participants $\geq 50$ years were employed ( $p$-value 0.000 ). However, since the start of the COVID-19 pandemic and the date they completed the survey, 12 (23.5\%) participants $<50$ years and 9 (39.1\%) participants $\geq 50$ years ( $p$-value 0.176 ) experienced a full or partial loss of employment. Furthermore, $42.1 \%$ of participants $<50$ years and $27.9 \%$ of participants $\geq 50$ years reported having expenses that they were worried about paying as a result of the COVID-19 pandemic ( $p$-value 0.023 ). Among participants $<50$ years, the most common expenses of concern included cancer treatments $(60.4 \%)$, groceries (54.7\%), and car payments $(50.9 \%)$ (Figure 1$)$. 
With respect to mental health outcomes, the mean score for all participants with regards to the GAD-7 was $6.8 \pm 5.5$, and for those $<50$ years as $7.4 \pm 5.1$ and for those $\geq 50$ years, as $5.9 \pm 5.9$ (p-value 0.042 ), suggesting that younger participants were more likely to experience anxiety during the COVID-19 pandemic. When we applied a cut-off value of $\geq 10$ to define the presence of anxiety, we found that $26.6 \%$ of participants were classified as having anxiety including $29.7 \%$ of participants $<50$ years and $23.0 \%$ of participants $\geq 50$ years ( $p$-value 0.267 ). With respect to scores on the PHQ-9, the mean score for all participants was $7.7 \pm 5.7$, and $8.3 \pm 5.3$ for participants $<50$ years and $7.0 \pm 6.1$ for participants $\geq 50$ years, respectively ( $p$-value 0.090$)$. When we applied a cut-off value of $\geq 10$ to define the presence of depression, we found that $30.0 \%$ of participants overall were considered as having depression, including $32.2 \%$ of participants $<50$ years and $27.4 \%$ of participants $\geq 50$ years ( $p$-value 0.448).

With regards to psychosocial outcomes, in assessing loneliness using the UCLA3, the mean score for all participants was $5.2 \pm$ 2.0 and $5.4 \pm 1.9$ for participants $<50$ years and $4.9 \pm 2.0$ for those $\geq 50$ years (p-value 0.116 ). Applying a cut-off value of $\geq 6$ to define the presence of loneliness, resulted in 97 (43.3\%) of all participants classified as having loneliness, including $46.1 \%$ of participants $<50$ years and $40.2 \%$ of participants $\geq 50$ years ( $p$-value 0.368 ). When asked about social isolation, the mean score on the LSNS6 for all participants was $16.9 \pm 6.0$ and $17.8 \pm 5.8$ for participants $<50$ years and $15.9 \pm 6.0$ for those $\geq 50$ years, (pvalue 0.019 ). The lower mean score on this scale suggests that older participants were more likely to experience social isolation during the COVID-19 pandemic. When we applied a cut-off value of $<12$, we found that $45(19.8 \%)$ of all participants experienced social isolation including $13.4 \%$ of participants $<50$ years and $26.8 \%$ of participants $\geq 50$ years ( $p$-value 0.011 ).

Table 2 shows results for multivariable linear regression models evaluating determinants of having higher anxiety and depression symptom scores among participants. Age at cancer diagnosis is a predictor of anxiety, with a higher age predicting a lower average score on the GAD-7 ( $B=-0.05$; $p$-value 0.047$)$, suggesting that younger cancer patients were more likely experience anxiety during the COVID-19 pandemic. Other predictors of increased anxiety were worrying about paying household expenses $(B=1.42 ; p$-value 0.034$)$, social isolation $(B=2.15 ; p$-value 0.017$)$ and depression $(B=6.67 ; p$-value $<.0001)$ (Table

$2 A)$. With regards to depression (Table 2B), both loneliness $(B=3.77 ; p$-value $<.0001)$ and anxiety $(B=6.54 ; p$-value $<.0001)$ were identified as predictors of higher average scores on the PHQ-9. We also found a negative association with level of education, particularly, individuals with secondary school or less had lower average scores on the PHQ-9 ( $B=-2.00$; $p$-value 0.005).

Finally, we assessed patterns of utilization of mental health care during the COVID-19 pandemic. Altogether, 71 (29.8\%) participants indicated that they were currently receiving treatment for anxiety or depression during the COVID-19 pandemic, including $32.5 \%$ of participants $<50$ years and $26.8 \%$ of participants $\geq 50$ years ( $p$-value 0.33 ). As well, $31.5 \%$ of participants indicated use of medication(s), such as antidepressants and anxiolytics. When stratified according to age, corresponding proportions were $32.5 \%$ of participants $<50$ years and $30.5 \%$ of those $\geq 50$ years indicated (p-value 0.755 ). When we asked which provider's participants accessed to for mental health care or support, the most commonly reported were family doctors ( $<50$ years $77.8 \% ; \geq 50$ years $75.9 \%$; $p$-value 0.732 ) and nurses ( $<50$ years $43.7 \% ; \geq 50$ years $33.0 \%$; $p$-value 0.093 ), with similar patterns between younger and older participants. The least common providers that participants had access to were those who specialized in mental health care, namely psychotherapists ( $<50$ years $10.3 \%$; $\geq 50$ years $3.6 \%$; $p$-value 0.044 ), psychiatrists ( $<50$ years $24.6 \%$; $\geq 50$ years $10.7 \%$; $p$-value 0.005 ), and psychologists ( $<50$ years $22.2 \%$; $\geq 50$ years $11.6 \%$; p-value 0.030 ) (Figure 2 ). However, we noted higher utilization of care from these providers among participants $<50$ as compared to those $\geq 50$ years. Finally, when asked about the mode of delivery of these mental health care, $51.4 \%$ of participants $<50$ years and $24.7 \%$ of participants $\geq 50$ years reported that they had received these virtually during the COVID-19 pandemic ( $p$-value 0.001).

\section{Discussion}

We conducted a cross-sectional Internet-based survey aimed at understanding mental and psychosocial health impacts of the COVID-19 pandemic among individuals undergoing active cancer treatment, with findings suggesting substantial proportions of participants experiencing anxiety (26.6\%), depression (30.0\%), loneliness (43.3\%), and social isolation (19.8\%). Unique to our study, comparing how the COVID-19 pandemic impacted individuals diagnosed with cancer $<50$ and $\geq 50$ years of age, revealed differences between groups. Specifically, we found that younger participants were more likely to experience anxiety, have expenses that they were worried about paying, and use mental health. We additionally found that older participants were more 
likely to experience social isolation during the COVID-19 pandemic. We also noted higher utilization of mental health care from specialist providers among participants $<50$ as compared to those $\geq 50$ years. Altogether our findings provide better understanding of the mental health burden during the COVID-19 pandemic among individuals undergoing active treatment for cancer, with implications for informing areas for better support.

With anecdotal reports on the mental health impacts of the COVID-19 pandemic among patients with cancer, an implication of our study was quantifying the extent of these, particularly with respect to anxiety in $26.6 \%$ of participants and depression in $30.0 \%$. With respect to anxiety, we found age at cancer diagnosis is a significant predictor, with younger participants having higher average scores on the GAD-7. This finding is supported by results from a 2012 Canadian mental health survey which found that that generalized anxiety disorder is most prevalent among middle-aged adults (35-54 years). ${ }^{17}$ Furthermore, research on the general population during the COVID-19 pandemic has shown that a younger age is a predictor of anxiety. ${ }^{18-20}$ Indeed, as an already vulnerable patient population, mental health disorders among patients with cancer have been associated with negative outcomes including poor treatment adherence, decreased quality of life, and suicide ideation. ${ }^{21}$ As such, higher levels of anxiety ( $29.7 \%<50$ years, $23.0 \% \geq 50$ years) and depression ( $32.2 \%<50$ years, $27.4 \% \geq 50$ years) during a global pandemic, as suggested by our findings, may have significant negative implications for health outcomes, particularly among younger patients with cancer. Aside from age at diagnosis, other significant determinants of anxiety as suggested by multiple linear regression models included worries about paying household expenses and concomitant depression. Other potential contributing factors may include delays in treatment and changes in oncology care which have been reported during the COVID-19 pandemic. ${ }^{22,23}$ With respect to depression, associated factors were level of education and social isolation, an important psychosocial factor that we also assessed in our study and discuss further below.

Relatedly, we assessed patterns of mental health care utilization among individuals with cancer during the COVID-19 pandemic. Of note, $29.8 \%$ of participants indicated that they were currently receiving care for anxiety or depression (at the time of survey completion). Furthermore, $31.5 \%$ of participants indicated use of medication(s), such as antidepressants and anxiolytics. These findings reflect the increase in the demand for mental health care, shown globally in the general population. ${ }^{1,2}$ We noted a greater tendency for patients $<50$ years of age, as compared to those $\geq 50$ years, to access care from specialists (e.g., psychiatrists, psychologists) as well as use virtual methods of care. As many aspects of healthcare have been forced to move online during the COVID-19 pandemic, vulnerable populations, such as older adults, have experienced access barriers. A study by the Pew Research Center in 2019 found that $27 \%$ of older adults in the United States are not on the Internet. ${ }^{24} \mathrm{~A}$ lack of an Internet connection creates a barrier to receiving care from patients' perspectives. From providers' perspectives studies have also suggested challenges such as telehealth training and patient privacy. ${ }^{25}$ Taken together, these barriers may explain why cancer patients, particularly those who are older, may not be accessing/receiving necessary mental health care during the COVID-19 pandemic.

Aside from mental health outcomes, we assessed psychosocial outcomes, particularly loneliness and social isolation. These are particularly relevant given that in efforts to slow the transmission of COVID-19, public health measures, such as physical distancing, have been implemented across jurisdictions ${ }^{26}$. However, approaches at the individual (e.g., self-isolation) and community (e.g., closures) levels ${ }^{27}$ significantly affect social structures and healthcare interactions, particularly for vulnerable patient populations such as patients with cancer who have with high degrees of need. In particular, we found that social isolation was more frequently reported among participants $\geq 50$ years. Our finding of $26.8 \%$ of participants $\geq 50$ years being classified as isolated is similar to findings by Aoki et al. ${ }^{28}$ in which they found that the rate of social isolation in older adults within the general population in Japan during the COVID-19 pandemic was 27.3\%. Previous research has shown that social isolation can have negative health outcomes including early mortality, particularly among older adults. ${ }^{29-31}$ Furthermore, Fleisch Marcus et al. ${ }^{29}$ conducted a population based study in 2017 in the United States and found that that social isolation was associated with increased cancer mortality (hazard ratio $1.25,95 \%$ confidence interval 1.01 to 1.54). As an already vulnerable population during the COVID-19 pandemic, it is important to understand the availability of social interactions and/or supports to cancer patients, particularly those who are older. 
The strengths and limitations of our study warrant discussion. We recruited participants across the age spectrum and representing many different types of cancer. By hosting the survey online, we acknowledge that our study sample is biased towards individuals with Internet access. The COVID-19 pandemic created a challenge as normally we would try to mitigate this bias by issuing in person paper surveys; however, with physical distancing measures in place, this was not possible. Additionally, despite our ability to recruit participants worldwide, our sample is largely based on residents in high-income countries with a post-secondary education. We recognize that these participants may have more access to mental health and social services when compared to low-income countries and populations. Furthermore, findings of gaps in mental health care may be even more exacerbated in such low resource settings.

Altogether, results of our study demonstrate the negative impact that the COVID-19 pandemic has had on the mental and psychosocial health of patients with cancer undergoing active treatment across the age spectrum. Identifying unique vulnerabilities in each age group have implications for informing specific areas for supporting patients through the COVID-19 pandemic.

\section{Declarations}

Funding: Dr. De Vera is a Tier 2 Canada Research Chair and a Michael Smith Foundation for Health Research Scholar.

Dr. Loree is a Michael Smith Foundation for Health Research Health Professional Investigator.

Disclosure statement: Dr. Loree reports grants and personal fees from Amgen, personal fees from Pfizer, grants and personal fees from Ipsen, personal fees from Novartis, grants from Foundation Medicine, personal fees from Eisai, personal fees from Bayer, grants from AstraZeneca, outside the submitted work.

Availability of Data: The data is not available for publication

Code Availability: The code is not available for publication

Contributions: Conceptualization: H.D., M.A.D.V.; Methodology: H.D., AH, AS, J.M.L., M.A.D.V.; Formal Analysis: H.D., A.S., M.A.D.V. Writing-original draft preparation: H.D., M.A.D.V.; Writing-review and editing and final approval: all authors; Supervision: M.A.D.V.

Ethics Approval: Approval was obtained from the ethics committee of University of British Columbia. The procedures used in this study adhere to the tenets of the Declaration of Helsinki.

Consent to Participate: Informed consent was obtained from all individual participants included in the study.

Consent for Publication: N/A

\section{References}

1. Titov N, Staples L, Kayrouz R et al (2020) Rapid report: Early demand, profiles and concerns of mental health users during the coronavirus (COVID-19) pandemic. Internet Interv 21:100327

2. Marshall JM, Dunstan DA, Bartik W (2020) The role of digital mental health resources to treat trauma symptoms in Australia during COVID-19. Psychol Trauma 12:S269-Ss271

3. British Columbia Ministry of Health. COVID-19 information for those with chronic health conditions. In: BC Centre for Disease Control, editor. British Columbia, 2020

4. Memorial Sloan Kettering Cancer Center. What You Should Know about Social Distancing, Especially if You Have Cancer. Available from URL: https://www.mskcc.org/coronavirus/what-you-should-know-about-social-distancing-especially-if-youhave [accessed July 24, 2020]

5. Košir U, Loades M, Wild $J$ et al. The impact of COVID-19 on the cancer care of adolescents and young adults and their wellbeing: Results from an online survey conducted in the early stages of the pandemic. Cancer.n/a

Page 6/14 
6. Belot M, Choi S, Jamison JC, Papageorge NW, Tripodi E, Van den Broek-Altenburg E. Unequal Consequences of Covid 19 across Age and Income: Representative Evidence from Six Countries2020

7. Mann FD, Krueger RF, Vohs KD (2020) Personal economic anxiety in response to COVID-19. Personality Individ Differ 167:110233

8. Adams-Prassl A, Boneva T, Golin M, Rauh C (2020) Inequality in the Impact of the Coronavirus Shock: New Survey Evidence for. University of Cambridge Faculty of Economics, the

9. Dau H, Saad El Din K, McTaggart-Cowan H, Loree JM, Gill S, De Vera MA. Health information seeking behaviors among individuals with young-onset and average-onset colorectal cancer: an international cross-sectional survey. Supportive Care in Cancer. 2020

10. Dau H, Safari A, Saad El Din K et al (2020) Assessing how health information needs of individuals with colorectal cancer are met across the care continuum: an international cross-sectional survey. BMC Cancer 20:1031

11. Spitzer RL, Kroenke K, Williams JBW, Löwe B (2006) A Brief Measure for Assessing Generalized Anxiety Disorder: The GAD7. Arch Intern Med 166:1092-1097

12. Kroenke K, Spitzer RL, Williams JBW (2001) The PHQ-9. J Gen Intern Med 16:606-613

13. Manea L, Gilbody S, McMillan D (2012) Optimal cut-off score for diagnosing depression with the Patient Health Questionnaire (PHQ-9): a meta-analysis. Cmaj 184:E191-E196

14. Lubben J, Blozik E, Gillmann G et al (2006) Performance of an abbreviated version of the Lubben Social Network Scale among three European community-dwelling older adult populations. Gerontologist 46:503-513

15. Ge L, Yap CW, Ong R, Heng BH (2017) Social isolation, loneliness and their relationships with depressive symptoms: A population-based study. PLOS ONE 12:e0182145

16. Hughes ME, Waite LJ, Hawkley LC, Cacioppo JT (2004) A Short Scale for Measuring Loneliness in Large Surveys: Results From Two Population-Based Studies. Research on aging 26:655-672

17. Watterson RA, Williams JVA, Lavorato DH, Patten SB (2017) Descriptive Epidemiology of Generalized Anxiety Disorder in Canada. The Canadian Journal of Psychiatry 62:24-29

18. Solomou I, Constantinidou F (2020) Prevalence and predictors of anxiety and depression symptoms during the CoViD-19 pandemic and compliance with precautionary measures: age and sex matter. Int J Environ Res Public Health 17:4924

19. Hyland P, Shevlin M, McBride $O$ et al. Anxiety and depression in the Republic of Ireland during the COVID-19 pandemic. Acta Psychiatrica Scandinavica.n/a

20. Nwachukwu I, Nkire N, Shalaby R et al. COVID-19 Pandemic: Age-Related Differences in Measures of Stress, Anxiety and Depression in Canada. International journal of environmental research and public health. 2020;17

21. Barrera I, Spiegel D (2014) Review of psychotherapeutic interventions on depression in cancer patients and their impact on disease progression. International Review of Psychiatry 26:31-43

22. Mayor S (2020) COVID-19: impact on cancer workforce and delivery of care. The Lancet Oncology 21:633

23. Akula SM, Abrams SL, Steelman LS et al (2020) Cancer therapy and treatments during COVID-19 era. Advances in Biological Regulation 77:100739

24. Anderson M, Perrin A, Jiang J, Kumar M. 10\% of Americans don't use the internet. Who are they. Pew Research Center. 2019;22

25. Taylor CB, Fitzsimmons-Craft EE, Graham AK (2020) Digital technology can revolutionize mental health services delivery: The COVID-19 crisis as a catalyst for change. Int J Eat Disord 53:1155-1157

26. Anderson RM, Heesterbeek H, Klinkenberg D, Hollingsworth TD (2020) How will country-based mitigation measures influence the course of the COVID-19 epidemic? The Lancet 395:931-934

27. Government of Canada. Community-based measures to mitigate the spread of coronavirus disease (COVID-19) in Canada. Available from URL: https://www.canada.ca/en/public-health/services/diseases/2019-novel-coronavirus-infection/healthprofessionals/public-health-measures-mitigate-covid-19.html [accessed April 5, 2020, 2020] 
28. Aoki T, Yamamoto Y, Ikenoue T et al (2018) Social Isolation and Patient Experience in Older Adults. The Annals of Family Medicine 16:393

29. Fleisch Marcus A, Illescas AH, Hohl BC, Llanos AA (2017) Relationships between social isolation, neighborhood poverty, and cancer mortality in a population-based study of US adults. PLOS ONE 12:e0173370

30. Laugesen K, Baggesen LM, Schmidt SAJ et al (2018) Social isolation and all-cause mortality: a population-based cohort study in Denmark. Scientific reports 8:4731

31. Shankar A, Hamer M, McMunn A, Steptoe A. Social Isolation and Loneliness: Relationships With Cognitive Function During 4 Years of Follow-up in the English Longitudinal Study of Ageing. Psychosomatic Medicine. 2013;75

\section{Tables}

Table 1. Participant demographic and cancer characteristics according to age at diagnosis 


\begin{tabular}{|c|c|c|c|c|}
\hline Characteristics & $\begin{array}{l}\text { All } \\
(n=238)\end{array}$ & $\begin{array}{l}<50 \text { years } \\
(n=126)\end{array}$ & $\begin{array}{l}\geq 50 \text { years } \\
(\mathrm{n}=112)\end{array}$ & p-value \\
\hline Gender (\%) & & & & 0.001 \\
\hline Female & $165(69.6)$ & 99 (78.6) & $66(59.5)$ & \\
\hline Male & $72(30.4)$ & $27(21.4)$ & $45(40.5)$ & \\
\hline Current age, year (mean [range]) & $52.8[18.6,93.0]$ & $41.4[18.6,67.2]$ & $65.6[51.6,93.0]$ & $<0.0001$ \\
\hline Age at diagnosis, year (mean [range]) & $49.1[16.4,82.8]$ & $38.4[16.4,49.9]$ & $61.0[50.0,82.8]$ & $<0.0001$ \\
\hline Country $^{b}(\%)$ & & & & $<0.0001$ \\
\hline Canada & $119(50.0)$ & $49(38.9)$ & $70(62.5)$ & \\
\hline USA & $81(34.0)$ & $60(47.6)$ & $21(18.7)$ & \\
\hline Other & $38(16.0)$ & $17(13.5)$ & $21(18.7)$ & \\
\hline Highest level of education (\%) & & & & 0.024 \\
\hline Šecondary school & 45 (18.9) & 17 (13.5) & $28(25.0)$ & \\
\hline Post-secondary & $193(81.1)$ & $109(86.5)$ & $84(75.0)$ & \\
\hline Residence (\%) & & & & 0.212 \\
\hline Rural & $44(18.9)$ & $21(17.2)$ & $23(20.7)$ & \\
\hline Suburban & $100(42.9)$ & $59(48.4)$ & $41(36.9)$ & \\
\hline Urban & $89(38.2)$ & $42(34.4)$ & $47(42.3)$ & \\
\hline Marital Status (\%) & & & & 0.001 \\
\hline Single & $38(16.0)$ & $30(23.8)$ & $8(7.1)$ & \\
\hline Married/common-law/co-habiting & $162(68.1)$ & $81(64.3)$ & $81(72.3)$ & \\
\hline Divorced/separated & $29(12.2)$ & $14(11.1)$ & $15(13.4)$ & \\
\hline Widowed & $9(3.8)$ & $1(0.8)$ & $8(7.1)$ & \\
\hline \multicolumn{5}{|l|}{ Race/ethnicityc (\%) } \\
\hline Asian & $8(3.4)$ & $4(3.2)$ & $4(3.6)$ & 0.877 \\
\hline Black & $7(3.0)$ & $6(4.8)$ & $1(0.9)$ & 0.078 \\
\hline Pacific Islander & $1(0.4)$ & $1(0.8)$ & $0(0.0)$ & 0.354 \\
\hline Hispanic & $5(2.1)$ & $4(3.2)$ & $1(0.9)$ & 0.221 \\
\hline Native/Aboriginal & $3(1.3)$ & $1(0.8)$ & $2(1.8)$ & 0.494 \\
\hline Middle Eastern & $6(2.5)$ & $6(4.8)$ & $0(0.0)$ & 0.019 \\
\hline White & $208(87.4)$ & $110(87.3)$ & $98(87.5)$ & 0.963 \\
\hline Other & $10(4.2)$ & $3(2.4)$ & $7(6.2)$ & 0.144 \\
\hline \multicolumn{5}{|l|}{ Cancer Type ${ }^{c}(\%)$} \\
\hline Breast & $62(26.1)$ & $30(23.8)$ & $32(28.6)$ & 0.414 \\
\hline Colorectal & $60(25.2)$ & $42(33.3)$ & $18(16.1)$ & 0.002 \\
\hline Lung & $16(6.7)$ & $2(1.6)$ & $14(12.5)$ & 0.001 \\
\hline Prostate & $15(6.3)$ & $0(0.0)$ & $15(13.4)$ & $<0.0001$ \\
\hline Leukemia & $10(4.2)$ & $9(7.1)$ & $1(0.9)$ & 0.016 \\
\hline Neuroendocrine & $13(5.5)$ & $4(3.1)$ & $9(8.0)$ & 0.101 \\
\hline Skin & $11(4.6)$ & $5(4.0)$ & $6(5.4)$ & 0.611 \\
\hline Thyroid & $11(4.6)$ & $10(7.9)$ & $1(0.9)$ & 0.010 \\
\hline Other & $60(25.2)$ & $32(25.4)$ & $28(25.0)$ & 0.944 \\
\hline Stage at diagnosis (\%) & & & & 0.562 \\
\hline Štage 0 & $2(0.9)$ & $1(0.8)$ & $1(0.9)$ & \\
\hline Stage I & $22(9.4)$ & $8(6.4)$ & $14(12.7)$ & \\
\hline Stage II & $30(12.8)$ & $18(14.4)$ & $12(10.9)$ & \\
\hline Stage III & 39 (16.6) & $23(18.4)$ & $16(14.5)$ & \\
\hline Stage IV & $105(44.7)$ & $54(43.2)$ & $51(46.4)$ & \\
\hline Do not know & 37 (15.7) & $21(16.8)$ & $16(14.5)$ & \\
\hline Treatment time (\%) & & & & 0.037 \\
\hline Less than 3 months & 46 (19.7) & $30(24.0)$ & $16(14.7)$ & \\
\hline 3-12 months & 71 (30.3) & $42(33.6)$ & $29(26.6)$ & \\
\hline Over 12 months & $117(50.0)$ & $53(42.4)$ & $64(58.7)$ & \\
\hline \multicolumn{5}{|l|}{ Treatment modality $^{\mathrm{c}}(\%)$} \\
\hline Radiation & $65(27.3)$ & $35(27.8)$ & $30(26.8)$ & 0.864 \\
\hline Oral chemotherapy & $51(21.4)$ & $30(23.8)$ & $21(18.7)$ & 0.342 \\
\hline Infusion chemotherapy & $122(51.3)$ & 77 (61.1) & $45(40.2)$ & 0.001 \\
\hline Surgery & 73 (30.7) & $43(34.1)$ & $30(26.8)$ & 0.220 \\
\hline Immunotherapy & 35 (14.7) & 15 (11.9) & 20 (17.9) & 0.202 \\
\hline Other & $70(29.4)$ & $27(21.4)$ & $43(38.4)$ & 0.004 \\
\hline Tested for COVID-19 (\%) & & & & 0.027 \\
\hline No & $181(82.3)$ & 90 (76.9) & $91(88.3)$ & \\
\hline Yes & 39 (17.7) & $27(23.1)$ & $12(11.6)$ & \\
\hline Negative test & $33(84.6)$ & $22(81.5)$ & 11 (91.7) & 0.533 \\
\hline Positive test & $2(5.1)$ & $1(3.7)$ & $1(8.3)$ & \\
\hline Waiting for results & $3(7.7)$ & $3(11.1)$ & $0(0.0)$ & \\
\hline Prefer not to answer & $1(2.6)$ & $1(3.7)$ & $0(0.0)$ & \\
\hline
\end{tabular}


${ }^{\mathrm{a} C a l c u l a t e d}$ using Chi-square test

${ }^{\mathrm{b}}$ Australia, France, Greece, Granada, Ireland, Netherlands, South Africa, Trinidad and Tobago, and United Kingdom

${ }^{\mathrm{c}}$ Multiple response answer

Table 2. Determinants of having anxiety and depression among cancer patients undergoing active treatment during the COVID-19 pandemic 


\begin{tabular}{|c|c|c|c|c|c|c|c|c|}
\hline & Estimate & $\begin{array}{c}\text { Standard } \\
\text { Error }\end{array}$ & P-value & $\begin{array}{c}95 \% \\
\text { Confidence } \\
\text { Limits }\end{array}$ & Estimate & $\begin{array}{c}\text { Standard } \\
\text { Error }\end{array}$ & P-value & $\begin{array}{c}95 \% \\
\text { Confidence } \\
\text { Limits }\end{array}$ \\
\hline Age at diagnosis & -0.05 & 0.03 & 0.047 & $\begin{array}{c}(-0.11, \\
0.00)\end{array}$ & -0.01 & 0.02 & 0.588 & $\begin{array}{c}(-0.06, \\
0.03)\end{array}$ \\
\hline
\end{tabular}
(ref)

Not breast

Breast

$\begin{array}{llll}1.09 & 1.37 & 0.430 & (-1.62 \\ & & & 3.80)\end{array}$

Not

colorectal (ref)

Colorectal (ref)

Not lung

$\begin{array}{llll}0.26 & 1.28 & 0.842 & (-2.28 \\ 2.79)\end{array}$

$-1.27$

1.25

0.753

$(-2.85$, 2.07)

Lung
$-0.15$
1.43
(-2.98,
$-0.25$
1.30
0.845
$(-2.82$,
2.79)

Not prostate (ref)

Prostate

$-0.74$

$\begin{array}{lll} & \\ 1.75 & 0.673 \quad & (-4.18 \\ 2.71)\end{array}$ (ref)

Not thyroid

0.58

1.58

0.714

$(-2.53$, 3.69)

Thyroid

$\begin{array}{llll}-2.39 & 1.77 & 0.180 & (-5.89 \\ 1.11)\end{array}$
(ref)

Not leukemia

$\begin{array}{llll}0.40 & 1.84 & 0.830 & (-3.24 \\ 4.03)\end{array}$

2.40

1.60

0.135

$(-0.76$,

Leukemia

Not skin (ref)

$-2.01$

1.67

0.231

$(-5.31$

Skin

Not
neuroendocrine

$\begin{array}{llll}-0.20 & 1.69 & 0.907 & (-3.54 \\ 3.14)\end{array}$

0.24

1.53

0.877

(-2.78,

(ref)

\begin{tabular}{|c|c|c|c|c|c|c|c|c|}
\hline Neuroendocrine & -0.80 & 1.76 & 0.650 & $\begin{array}{c}(-4.28, \\
2.68)\end{array}$ & -1.63 & 1.60 & 0.310 & $\begin{array}{c}(-4.78, \\
1.52)\end{array}$ \\
\hline $\begin{array}{l}\text { Not other } \\
\text { (ref) }\end{array}$ & & & & & & & & \\
\hline Other & 0.18 & 1.22 & 0.885 & $\begin{array}{c}(-2.24, \\
2.59)\end{array}$ & -0.60 & 1.11 & 0.587 & $\begin{array}{c}(-2.79 \\
1.58)\end{array}$ \\
\hline
\end{tabular}

Gender

Male (ref)

Female

1.05

0.82

$\begin{array}{ll} & (-0.57 \\ 0.202 & 2.68)\end{array}$

$-0.27$

0.75

0.716

(-1.75,

Highest level of education

Postsecondary

or more (ref)

Secondary

school or less

Treatment

modality

(ref)

No radiation

Radiation

No

$-1.20$

0.79

$(-2.75$,

$-2.00$

0.71

0.005

$(-3.40$, $-0.60)$

chemotherapy

oral (ref)

Chemotherapy

$\begin{array}{llll}-0.35 & 0.80 & 0.665 & (-1.92 \\ 1.23)\end{array}$

0.98

0.71

0.172

(-0.43,

2.38)

oral

0.50

0.78

0.523

$(-1.04$,

1.38

0.71

0.052

$(-0.01$,

2.78) 
No

Chemotherapy

infusion (ref)

Chemotherapy

infusion

$-0.56 \quad 0.78$

1.04

0.71

0.145

$(-0.36$,

$(-2.11$

(ref)

No surgery

Surgery

Worried about

paying

household

expenses

No (ref)

Yes

$0.11 \quad 0.74$

0.477

0.99)

2.43)

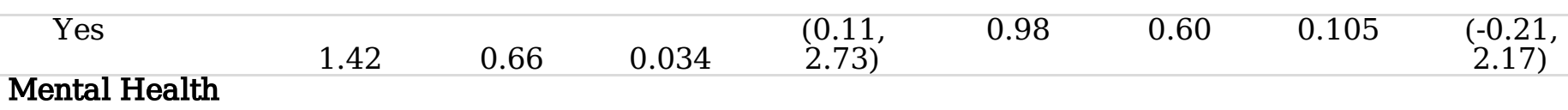

Not lonely

(ref) ${ }^{\mathrm{a}}$

Lonely $^{\mathrm{a}}$

$-0.12$

0.74

$(-1.58$,

$(-1.36$
$1.58)$

0.09

0.67

0.889

$(-1.24$, 1.43)

Not isolated $(\text { ref })^{\mathrm{b}}$

Isolated $^{\mathrm{b}}$

$\begin{array}{llll}2.15 & 0.89 & 0.017 & (0.40 \\ \end{array}$

Not 3.90)

1.42

3.77

0.62

(2.55,

4.99)

depressed (ref) ${ }^{\mathrm{C}}$

Depressed $^{\mathrm{c}}$

Not anxious

6.67

$0.78<0.0001$

(5.14,

8.21)

(ref) $^{\mathrm{d}}$

Anxious $^{\mathrm{d}}$

6.54

0.66

$<0.0001$

(5.24,

$7.85)$

a UCLA-3 scale; cut off $\geq 6$

${ }^{\mathrm{b}}$ LSNS6 scale; cut off $<12$

c PHQ-9 scale; cut off $\geq 10$

d GAD-7 scale; cut off $\geq 10$

Figures 


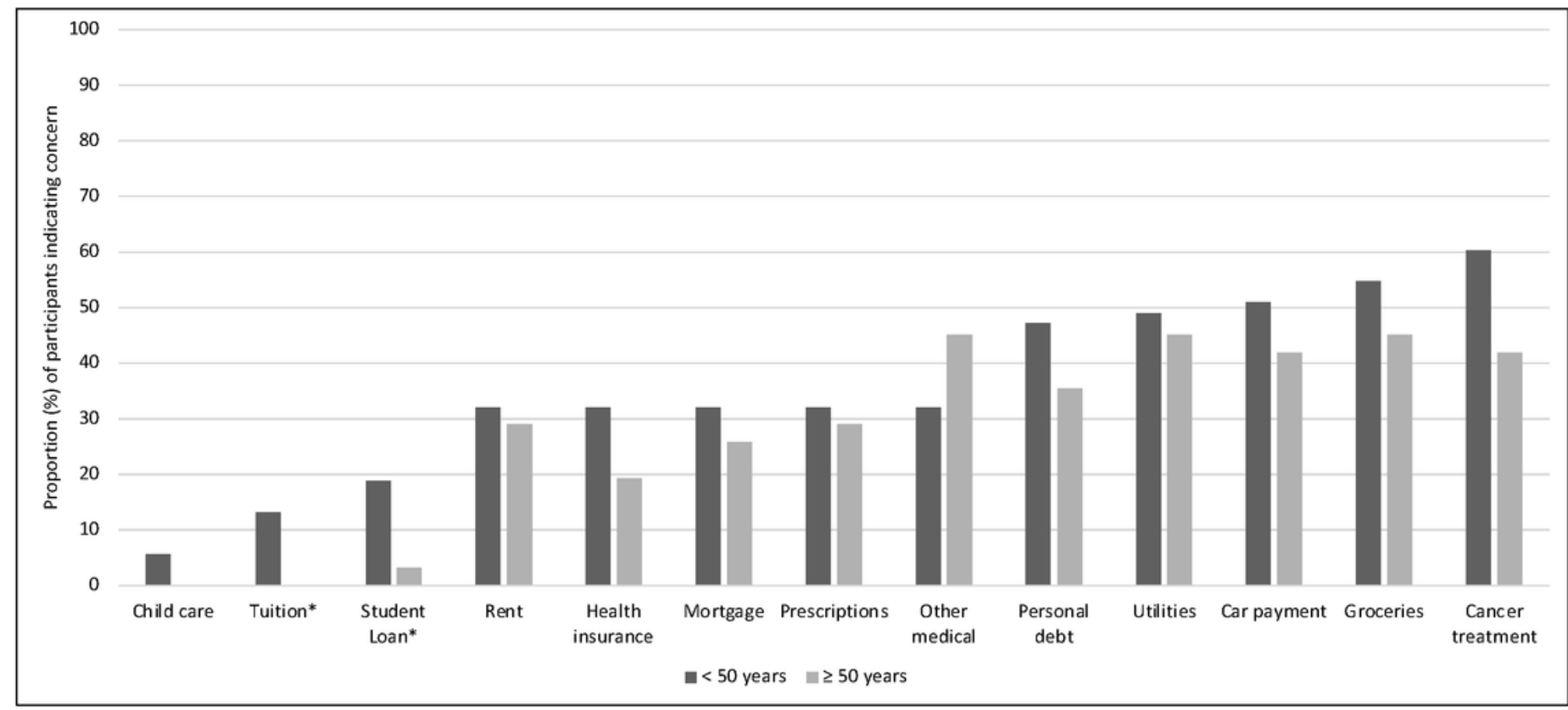

*chi-square test $<.05$

Figure 1. Expenses that participants were worried about paying during the COVID-19 pandemic according age at cancer diagnosis

\section{Figure 1}

Expenses that participants were worried about paying during the COVID-19 pandemic according age at cancer diagnosis

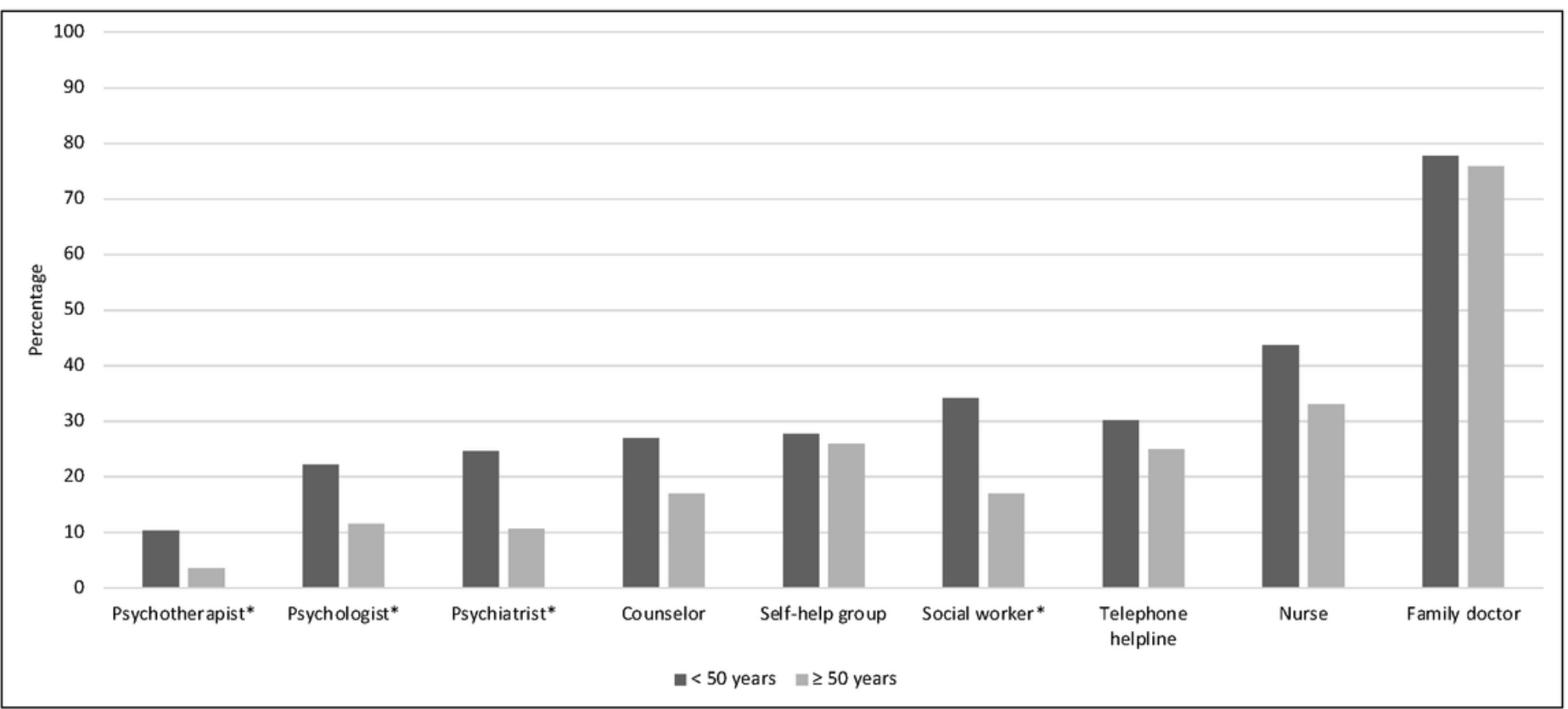

*chi-square test $<.05$

Figure 2. Mental health services accessed by participants during the COVID-19 pandemic according to age at cancer diagnosis

Figure 2 


\section{Supplementary Files}

This is a list of supplementary files associated with this preprint. Click to download.

- Supplementary1.pdf 